\title{
Waste Management and Symbiosis for Waste Valorization
}

\author{
Maria Loizidou ${ }^{1}$
}

Received: 31 August 2015/Accepted: 2 September 2015/Published online: 5 September 2015

(C) Springer Science+Business Media Dordrecht 2015

Sustainable solid waste management is a necessary prerequisite for all societies today in order to protect the environment and human health. The environmental burden caused by the high waste generation rates has to be effectively dealt with, since the link between economic growth and waste should be broken and decoupling should be achieved. Furthermore, it is necessary to focus on basic and applied research in order to find the best ways and solutions so as to promote the valorization of the generated waste from a huge number of sources either by manufacturing new products with high added value or producing energy. Research and technology have the power to identify additional innovative ways so as to make efficient use of the value hidden within the different waste streams generated and expand the life cycle of goods and products with multi-side positive effects. The waste valorization as source or through symbiosis approach is associated with resource efficiency and circular economy.

This Special Issue entitled: "Waste Management and Symbiosis for Waste Valorization" includes the best papers presented in two conferences, namely, the ATHENS2014 2nd International Conference on Sustainable Solid Waste Management (http://www.athens2014.biowaste.gr) held at Royal Hotel in Athens from 12th to 14th June 2014 and the SYMBIOSIS 2014 Conference (http://www.conference 2014.esymbiosis.eu) held at President Hotel in Athens from 19th to 21 st June 2014.

Maria Loizidou

mloiz@chemeng.ntua.gr

1 Unit of Environmental Science and Technology, School of Chemical Engineering, National Technical University of Athens, 9 Heroon Polytechniou Street, Zographou Campus, 15773 Athens, Greece
The ATHENS 2014 Conference aimed to address the significant issues for sustainable solid waste management through the promotion of effective technologies and success practices, stimulating the interest of scientific community, competent authorities and public and inform them about the latest developments in the field of municipal solid waste management. Biological Treatment (composting and anaerobic digestion), the treatment at central facilities, waste prevention and separation at source with emphasis on biowaste also constituted priority subjects of the rich conference agenda. Special attention was drawn on compost and its quality, as well as recycling. The Conference was organized within the LIFE+ ATHENS-BIOWASTE project (LIFE10 ENV/GR/000605) (www.biowaste.gr) dealing with the separate collection and composting of biowaste.

The SYMBIOSIS 2014 Conference aimed to address the significant issue of utilization of the generated industrial waste through the promotion of effective technologies and safe practices. The Conference focused mainly on industrial symbiosis, the sharing of services, utility, and byproduct resources among industries in order to add value, reduce costs and improve the environment. The Conference was organized in the framework of the LIFE+ eSYMBIOSIS project (LIFE09 ENV/GR/000300) (www.esym biosis.eu) building the Industrial Symbiosis concept with the use of a developed platform.

Industrial Symbiosis should be considered as one of the solutions to be addressed to achieve more efficient processing, resource and energy efficient systems for the process industry. It aimed to stimulate the interest of scientists, industries and associations and inform them about creating economic and environmental value through interfirm collaboration moving towards a near-zero waste society. 
The articles in this issue have been listed under four different divisions. The first one refers to waste management, characterization and carbon footprint and includes five papers. The paper of Lasaridi and colleagues deals with waste prevention scenarios using a web-based tool targeting at local authorities. Malamis and colleagues have worked in the field of biowaste compositional analysis presenting the first results for the case of Greece, while the work of Dias-Ferreira and colleagues is relevant to a Portuguese example of door-to-door collection of food and kitchen waste in city centers. Next, a review paper by Xevgenos and colleagues presents good examples for recycling municipal solid waste at municipal level and the paper of Bourka and colleagues refers to the carbon footprint of biowaste collection at source and treatment.

Composting, anaerobic digestion biofuel production is the subject of the second division of the special issue. The first paper of this division (Gao and colleagues) deals with co-composting corn stalk or rice husk with swine waste, the next five papers are related to anaerobic digestion and the next three to biofuel production. In the field of anaerobic digestion Lopes and colleagues present studies on the chemical stabilization of digestate from mechanically recovered organic fraction of municipal solid waste, Micolucci and colleagues have made an analysis of meso/ thermo anaerobic digestion process applied to pressed biowaste, Antonopoulou and colleagues present results on the chemical pretreatment of sunflower straw biomass, discussing the effect on chemical composition and structural changes, Vlyssides and colleagues have worked on energy generation potential from agricultural residues and livestock manure and Bayard and colleagues have performed statistical analysis in order to correlate bio-physical and chemical characteristics of organic wastes and digestates to their anaerobic biodegradability. The last papers of this division are related to biofuels. More specifically, there is a paper on biodiesel and alternative collection systems (Caldeira and colleagues), a paper on lignocellulosic biomass fractionation as a pretreatment step for production of fuels and green chemicals (Kalogiannis and colleagues) and a paper about the biogas upgrading by a combination of innovative treatments based on carbonation of waste incineration residues (Lombardi and Carnavale).

The third division of the special issue refers to biomass thermal treatment and the valorization of residues including four papers. The assessment of pistachio shell biochar quality and its potential for adsorption of heavy metals is the subject of the first one by Komnitsas et al. and the second one by Vakalis and Baratieri is related to technological advancements in small scale biomass gasification in South Tyrol. The papers of Zabaniotou and colleagues on the management of olive grove pruning and solid waste from olive oil extraction via thermochemical processes and Tapali and colleagues on plant design and economics of rice husk ash exploitation as a pozzolanic material constitute the last papers of the division.

Eight papers have been included in the last division dealing with industrial symbiosis and valorization of specific waste streams. The first two papers by Tackmann et al. and Iacondini et al. are addressing industrial symbiosis. More specifically, the first paper deals with industrial symbiosis exchanges and developing guidelines towards realization and the next is related to feasibility of Industrial Symbiosis in Italy as an opportunity for economic development. Furthermore, four papers present specific examples of valorization of different waste streams. One paper focuses on the production of lightweight fillers from waste glass and paper sludge ash (Spathi and colleagues), the next paper by Tsoumani and colleagues targets at recycled aggregate as structural material, the third paper by Zoccola et al. refers to the production of organic nitrogen fertilizers from wool wastes through hydrolysis and the fourth paper presents feather waste recycle for producing biogas (Mézes and colleagues). Finally, the last two papers of the special issue by Valta and colleagues constitute review papers, one on enhancing value to olive oil production through waste and wastewater treatment and valorization and the other on valorisation opportunities in the slaughtering industry.

All 26 papers presented clearly show that significant attempts are made at international level so as to improve the waste management status. It is true that waste should be considered as a resource and, therefore, it is a must that waste should not end up in landfills. All potentials and prospects should be explored in order to achieve the protection of the environment and at the same time save resources by the exploitation of all available materials that are characterized as waste, promoting the symbiosis concept in practice.

I would especially like to thank Prof. Ange Nzihou, the Editor-in-Chief of WASTE and BIOMASS VALORIZATION for his trust and guidance, as well the LIFE+ Programme of the European Commission for the financial support of the ATHENS-BIOWASTE and the eSYMBIOSIS project, which are both considered by EC successful projects at European level. 